\title{
THE SUPERFICIAL PERONEAL TUNNEL SYNDROME
}

\author{
RESULTS OF TREATMENT BY DECOMPRESSION
}

JORMA STYF， PER MORBERG

From Östra Hospital, Gothenburg, Sweden

We diagnosed entrapment of the superficial peroneal nerve in 17 patients (19 legs) with a mean age of 41 years. In all cases, plain radiographs of the leg, nerve-conduction studies of the superficial peroneal nerve and measurement of the intramuscular pressure at rest after exercise were normal. Diagnostic tests for nerve compression during rest after exercise produced pain and clinical signs in all.

We performed decompression of the superficial peroneal tunnel in $\mathbf{1 4}$ patients and local fasciectomy in three. Fourteen patients $(\mathbf{8 0 \%})$ were free from symptoms or satisfied with the result.

J Bone Joint Surg [Br] 1997;79-B:801-3.

Received 24 March 1997; Accepted 9 April 1997

We have shown that normal conduction velocity at rest does not exclude entrapment of the superficial peroneal nerve. ${ }^{1}$ This is best diagnosed by clinical examination after exercise. $^{2}$

It has been shown that only $10 \%$ of patients with entrapment of the superficial peroneal nerve have a chronic lateral compartment syndrome ${ }^{1}$ and decompression of the whole lateral compartment by fasciotomy may therefore be unnecessary in those who do not have a compartment syndrome.

We have evaluated the results of treatment by decompression of the peroneal tunnel in patients with a tunnel syndrome, and by local fasciectomy in patients with entrapment of the nerve for other reasons. All the patients had the

J. Styf, MD, PhD, Associate Professor

P. Morberg, MD, Consultant Orthopaedic Surgeon

Department of Orthopaedics, Östra Hospital, S-416 85 Gothenburg,

Sweden.

Correspondence should be sent to Dr J. Styf.

(c)1997 British Editorial Society of Bone and Joint Surgery 0301-620X/97/57799\$2.00 clinical signs of nerve entrapment, normal nerve-conduction studies and a normal intramuscular pressure.

\section{PATIENTS AND METHODS}

We made a prospective study of 480 patients with chronic leg pain, 17 of whom were found to have entrapment of the superficial peroneal nerve. There were nine men and eight women with a mean age of 41 years (17 to 71$)$. Two patients had bilateral symptoms. They all gave their written informed consent for participation in the study, which was approved by the Ethical Committee of the University of Gothenburg.

The mean duration of pain and sensory dysfunction before diagnosis and treatment was four years ten months (1.5 to 11). No treatment had been successful. In all, plain radiographs of the leg, nerve-conduction studies and intramuscular pressures were normal. The symptoms had been initiated by trauma in four patients. Table I gives the details of the patients.

Clinical examination. Each patient was examined to record the range of movement of the hip, knee and ankle and the straight-leg raise test was performed. The stability of the knee and ankle was determined as was the presence of fascial defects. Patients with clinical signs of compression of the common peroneal nerve at the head of the fibula were excluded. Three provocation tests for nerve compression were undertaken at rest and then again at rest after exercise. ${ }^{1}$ In the first, pressure was applied over the anterior intermuscular septum while the patient actively dorsiflexed the ankle. In the second, the foot was passively plantar flexed and inverted at the ankle. Finally, while maintaining passive stretch, gentle percussion was applied over the course of the nerve. Pain or paraesthesia caused by any of these tests suggested entrapment of the superficial peroneal nerve.

Diagnostic criteria. Entrapment of the peroneal nerve was diagnosed when sensation over the dorsum of the foot was decreased and there was pain at rest or during an exercise test, and when at least the first two of the three provocation tests described above were positive.

A chronic compartment syndrome was diagnosed when the intramuscular pressure at rest after exercise exceeded 
Table I. Details of 17 patients with entrapment of the superficial peroneal nerve

\begin{tabular}{|c|c|c|c|c|c|c|c|c|}
\hline Case & $\begin{array}{l}\text { Age } \\
(\mathbf{y r})\end{array}$ & Gender & $\begin{array}{l}\text { Activity level } \\
\text { to pain }\end{array}$ & Cause & $\begin{array}{l}\text { Concomitant } \\
\text { symptoms }\end{array}$ & $\begin{array}{l}\text { Pain duration } \\
(\mathbf{m t h})\end{array}$ & $\begin{array}{l}\text { Postop activity } \\
\text { level without pain }\end{array}$ & $\begin{array}{l}\text { Subjective } \\
\text { evaluation }\end{array}$ \\
\hline 1 & 35 & M & Walking & Tunnel syndr & Venous insuff & 30 & Walking & Unchanged \\
\hline 2 & 64 & $\mathrm{~F}$ & Rest & Entrapment & & 84 & Running & Good \\
\hline 3 & 71 & $\mathrm{~F}$ & Rest & Entrapment & Venous insuff & 30 & Walking & Excellent \\
\hline 4 & 17 & M & Walking & Tunnel syndr & & 18 & Running & Good \\
\hline 5 & 28 & $\mathrm{~F}$ & Walking & Tunnel syndr & & 120 & At rest & Good \\
\hline 6 & 23 & M & Rest & Tunnel syndr & & 48 & Walking & Good \\
\hline 7 & 22 & M & Walking & Entrapment & Post fasciotomy & 36 & Walking & Unchanged \\
\hline 8 & 63 & M & Rest & Tunnel syndr & & 48 & Unlimited & Excellent \\
\hline 9 & 50 & M & Rest & Tunnel syndr & & 131 & Walking & Good \\
\hline 10 & 54 & M & Rest & Tunnel syndr & Trauma & 36 & Walking & Excellent \\
\hline 11 & 63 & $\mathrm{~F}$ & Rest & Tunnel syndr & Trauma & 48 & Running & Good \\
\hline 12 & 50 & $\mathrm{~F}$ & Rest & Tunnel syndr & Trauma & 34 & Unlimited & Good \\
\hline 13 & 27 & $\mathrm{~F}$ & Walking & Tunnel syndr & & 36 & Running & Good \\
\hline 14 & 55 & $\mathrm{~F}$ & Rest & Tunnel syndr & & 60 & Unlimited & Excellent \\
\hline 15 & 20 & $\mathrm{~F}$ & Running & Tunnel syndr & & & Unlimited & Good \\
\hline 16 & 27 & M & Walking & Tunnel syndr & Fracture & 120 & At rest & Unchanged \\
\hline 17 & 30 & M & Rest & Tunnel syndr & & & Running & Good \\
\hline
\end{tabular}

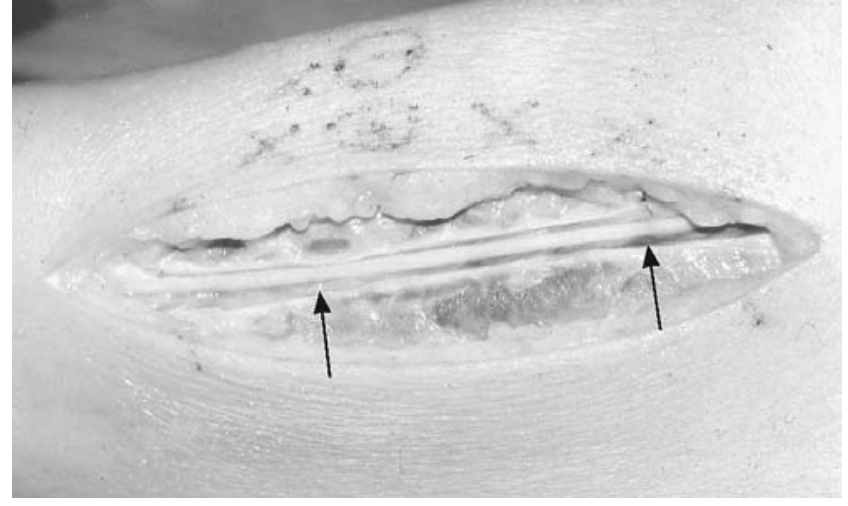

Fig. 1

Photograph at operation showing flattening of the nerve as it lies in the tunnel (between arrows) which has been decompressed.

$35 \mathrm{mmHg}$ and it took more than ten minutes for the elevated pressure to return to normal. ${ }^{3-5}$ The normal time for the postexercise pressure to return to normal was six minutes. ${ }^{5-7}$

A peroneal tunnel syndrome was diagnosed in patients with symptoms and signs of entrapment of the superficial peroneal nerve in whom at operation a fascial tunnel longer than $3 \mathrm{~cm}$ was found at the anterior intermuscular septum. ${ }^{1}$

Intramuscular pressure. This was measured by the meniscus method ${ }^{8}$ in the anterior and lateral compartments in five patients with exercise-induced leg pain. Recordings were made at rest after an exercise test which produced the clinical symptoms. The patients were allowed to choose their exercise, depending on their fitness and the time of the year, as follows: dorsiflexion of the ankle on a foot ergometer, walking indoors, or outdoor running on an 800 metre track.

Operative treatment. Before operation the site of nerve

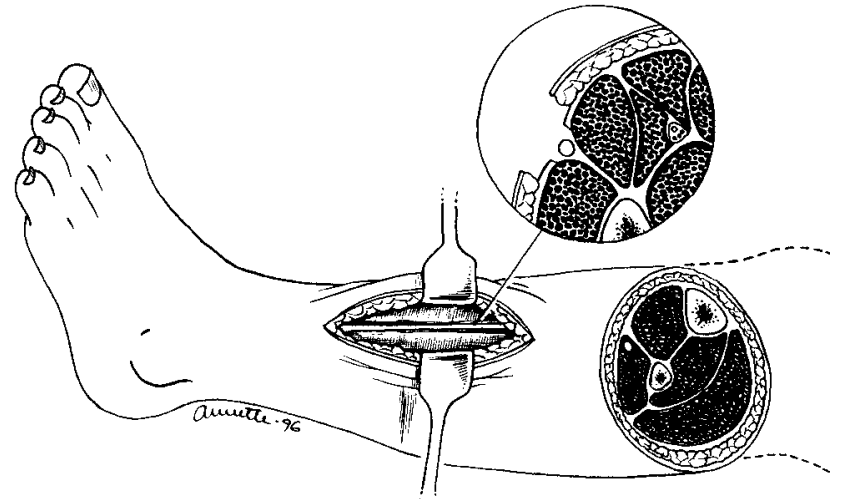

Fig. 2

Diagram of the anatomy of the superficial peroneal tunnel.

compression in the leg was identified by the first of the three provocation tests already described. ${ }^{1}$ Preoperative marking of the painful sites in the leg is important because of variation in the anatomy and an anomalous course of the nerve is common. ${ }^{1,9}$ Under general anaesthesia with a thigh tourniquet, a skin incision $6 \mathrm{~cm}$ long was made $1 \mathrm{~cm}$ dorsal to the markings of the painful sites (Fig. 1). The nerve was located at the proximal edge of the fascial defect in 15 patients and at the normal fascial exit in two. The roof of the peroneal tunnel was incised longitudinally until the nerve entered the belly of the peroneus longus muscle. The incision in the fascia was kept close to the anterior intermuscular septum (Fig. 2). The skin incision was extended proximally in patients with a long peroneal tunnel. In those with a fascial defect but no peroneal tunnel, the fascia was excised for about $2 \mathrm{~cm}$ proximally. The tourniquet was released and haemostasis carefully controlled. The skin was closed by a subcuticular suture. 
Walking was allowed with crutches four hours after the operation and full weight-bearing after 12 hours.

The patients with bilateral symptoms had operations separated by six months.

All patients were followed up at a minimum of two years by an unbiased observer (PM) who did not participate in their treatment. The mean follow-up was 26 months (18 to 36). The patients answered a questionnaire, made a pain drawing and were assessed clinically. Those who were free from symptoms and enjoyed unlimited physical activity were classified as excellent. Those who rated themselves as improved and satisfied, but with mild residual dysaesthesia or pain, were rated as good.

Statistical analysis. The results are given as mean values. The difference between values before and after operation was tested using Fisher's exact test.

\section{RESULTS}

Fourteen patients $(82 \%)$ were satisfied and three were not. Four were free from symptoms. Thirteen had some residual symptoms or complaints, of whom ten regarded themselves as satisfied. Three were not improved, but none became worse. Table I gives the details.

Of the 13 patients with residual symptoms two had aching legs, one had mild swelling in the leg and eight had pain during walking. Five had occasional calf muscle cramps, which were experienced only at night by three patients.

After operation four patients could undertake unlimited physical activity, in ten activity was increased but limited and in three it was unchanged. Ten patients had pain at rest before operation but only two had pain after $(\mathrm{p}<0.05)$.

The mean length of the peroneal tunnel was $10.7 \mathrm{~cm}$ (7 to 16) in ten patients and less than $3 \mathrm{~cm}$ in four. It was absent in three patients. In 14 patients the nerve in the peroneal tunnel was thin. In 12 of these there was a visible waist at the exit from the tunnel and in the 15 in whom the muscle herniated through the fascial defect.

\section{DISCUSSION}

Our patients had suffered disabling pain for a mean of four years and had clinical findings of nerve entrapment with normal nerve-conduction studies. Those with residual symptoms after operation were still satisfied because they had less pain and were able to be more active. Four of the oldest patients were satisfied because they had no pain while supine in bed and were able to tolerate a cover on top of their legs and feet. Pain drawings were helpful in detecting residual symptoms produced by concomitant diseases. Most of the older patients and some of the younger patients had venous insufficiency, and the younger posttraumatic pain which was unrelated to nerve entrapment.

The nerve must be decompressed by complete opening of the peroneal tunnel close to the anterior intermuscular septum to minimise the risk of residual irritation from the edge of the fascia and the muscle tissue, and to avoid muscle hernia (Fig. 2). Haemostasis after the tourniquet has been released and removed is especially important.

The differential diagnoses for the peroneal tunnel syndrome include the pseudoradicular pain syndrome, 1,10 chronic lateral compartment syndrome, fascial defects with muscle herniation ${ }^{11,12}$ and lipomata. ${ }^{13}$ The condition may be induced by an ankle sprain, ${ }^{14}$ fasciotomy of the anterior compartment in patients with chronic anterior compartment syndrome $^{1,2}$ or an anomalous course of the nerve. ${ }^{1,9}$ The nerve is compressed at the site of emergence from the lateral compartment. The clinical finding of extended pain over the anterior intermuscular septum at palpation was found to correlate with a peroneal tunnel syndrome.

Our study shows that complete fasciotomy is not necessary in patients with entrapment of the superficial peroneal nerve if they do not have a chronic lateral compartment syndrome. Treatment by decompression of the superficial peroneal tunnel is sufficient in patients with a peroneal tunnel syndrome. Those with compression of the peroneal nerve without a peroneal tunnel may be treated by local fasciectomy.

This study was funded by the University of Göteborg (LUA-funding), Gothenburg.

No benefits in any form have been received or will be received from a commercial party related directly or indirectly to the subject of this article.

\section{REFERENCES}

1. Styf J. Entrapment of the superficial peroneal nerve: diagnosis and treatment by decompression. J Bone Joint Surg [Br] 1989;71-B: 131-5.

2. Styf J. Diagnosis of exercise-induced pain in the anterior aspect of the lower leg. Am J Sports Med 1988;16:165-9.

3. Styf J, Körner L. Microcapillary infusion technique for measurement of intramuscular pressure during exercise. Clin Orthop 1986;207: 253-62.

4. Rorabeck CH, Bourne RB, Fowler PJ, Finlay JB, Nott L. The role of tissue pressure measurement in diagnosing chronic anterior compartment syndrome. Am J Sports Med 1988;16:143-6.

5. Reneman RS. The anterior and lateral compartmental syndrome of the leg due to intensive use of muscles. Clin Orthop 1975;113:69-80.

6. Rorabeck CH, Bourne RB, Fowler PJ. The surgical treatment of exertional compartment syndrome in athletes. J Bone Joint Surg [Am] 1983:65-A:1245-51.

7. Styf J, Körner L. Diagnosis of chronic anterior compartment syndrome of the lower leg. Acta Orthop Scand 1987;58:139-44.

8. Styf J. Evaluation of injection techniques in recording of intramuscular pressure. J Orthop Res 1989;7:812-6.

9. Adkison DP, Bosse MJ, Gaccione DR, Gabriel KR. Anatomical variations of the course of the superficial peroneal nerve. J Bone Joint Surg [Am] 1991;73-A:112-4.

10. Lowdon IMR. Superficial peroneal nerve entrapment; a case report. J Bone Joint Surg [Br] 1985;67-B:58-9.

11. Garfin S, Mubarak SJ, Owen CA. Exertional anterolateral-compartment syndrome: case report with fascial defect, muscle herniation, and superficial peroneal-nerve entrapment. J Bone Joint Surg [Am] 1977; 59-A:404-5.

12. McAuliffe TB, Fiddian NJ, Browett JP. Entrapment neuropathy of the superficial peroneal nerve: a bilateral case. J Bone Joint Surg [Br] 1985;67-B:62-3.

13. Banerjee T, Koons DD. Superficial peroneal nerve entrapment: report of two cases. J Neurosurg 1981;55:991-2.

14. Kernohan J, Levack B, Wilson JN. Entrapment of the superficial peroneal nerve: three case reports. J Bone Joint Surg [Br] 1985; 67-B:60-1. 